\title{
Prevalence and in vitro antifungal susceptibility of commensal yeasts in the external ear canal of cats
}

\author{
Sara Niae ${ }^{1}$, Chompoonek Yurayart ${ }^{2}$, Naris Thengchaisri ${ }^{3}$ and Panpicha Sattasathuchana ${ }^{3 *}$
}

\begin{abstract}
Background: Lifestyle factors such as hair length, the frequency of ear cleaning and bathing, age, cat rearing, and sex may contribute to opportunistic yeast infections in the external ear canal of cats. This study aimed to determine the prevalence of commensal yeast organisms in cats' external ear canals, evaluate their predisposing lifestyle factors, and test the susceptibility of Malassezia pachydermatis to antifungal agents.
\end{abstract}

Results: A total of 53 cats (33 male and 20 female) seronegative for feline leukemia virus and feline immunodeficiency virus were enrolled in this study. Their mean age ( \pm standard deviation) was 6.04 ( \pm 3.49 ) years. Fungal cultures and polymerase chain reaction tests were performed to identify the yeast species derived from the external ear canal. The association between lifestyle factors and the presence of M. pachydermatis was evaluated using Fisher's exact test. The susceptibility of $M$. pachydermatis to antifungal agents was also analyzed. $M$. pachydermatis was the most frequently recovered yeast species, with a prevalence of $50.94 \%$ (95\% confidence interval [CI]: 36.84-64.94\%). There was an association between hair length and a positive culture for $M$. pachydermatis $(p=0.0001)$. The odds of a negative culture for $M$. pachydermatis among short-haired cats was 11.67 ( $95 \% \mathrm{Cl}, 3.22-42.24)$ times higher than that among long-haired cats $(p=0.0002)$. There was also an association between the frequency of ear cleaning and the presence of $M$. pachydermatis $(p=0.007)$. The odds of a negative culture for M. pachydermatis in cats that were receiving ear cleaning at intervals of $\leq 2$ weeks was 5.78 ( $95 \% \mathrm{Cl}$, 1.67-19.94) times greater than that of cats receiving ear cleaning at intervals greater than 2 weeks or never $(p=0.0055)$. Ranges of minimum inhibitory concentrations (MICs) and minimum fungicidal concentrations for itraconazole, ketoconazole, miconazole, and terbinafine against M. pachydermatis were $\leq 0.063-4$ and $\leq 0.063-\geq 32$, $\leq 0.063-8$ and $0.125-\geq 32, \leq 0.063-\geq 32$ and $0.5-\geq 32$, and $\leq 0.016-1$ and $0.125-8 \mu \mathrm{g} / \mathrm{ml}$, respectively.

Conclusions: M. pachydermatis was the most commonly identified yeast organism in the external ear canal of healthy cats. Hair length and the frequency of ear cleaning played a role in the colonization of M. pachydermatis. The M. pachydermatis isolates had various MIC levels for common fungicides.

Keywords: Cat external ear canal, Commensal yeasts, In vitro antifungal susceptibility

\footnotetext{
*Correspondence: psatta99@gmail.com

${ }^{3}$ Department of Companion Animal Clinical Sciences, Faculty of Veterinary Medicine, Kasetsart University, 50 Ngamwongwan Rd, Latyao, Jatujak, 10900 Bangkok, Thailand

Full list of author information is available at the end of the article
}

(C) The Author(s). 2021 Open Access This article is licensed under a Creative Commons Attribution 4.0 International License, which permits use, sharing, adaptation, distribution and reproduction in any medium or format, as long as you give appropriate credit to the original author(s) and the source, provide a link to the Creative Commons licence, and indicate if changes were made. The images or other third party material in this article are included in the article's Creative Commons licence, unless indicated otherwise in a credit line to the material. If material is not included in the article's Creative Commons licence and your intended use is not permitted by statutory regulation or exceeds the permitted use, you will need to obtain permission directly from the copyright holder. To view a copy of this licence, visit http://creativecommons.org/licenses/by/4.0/ The Creative Commons Public Domain Dedication waiver (http://creativecommons.org/publicdomain/zero/1.0/) applies to the data made available in this article, unless otherwise stated in a credit line to the data. 


\section{Background}

Malassezia spp. is a commensal yeast found on the mucosa and skin of mammals. Overgrowth of this organism may cause a local or systemic disease in humans and cats [1, 2]. Malassezia pachydermatis is a nonlipid-dependent yeast species, and it is the most commonly isolated yeast organism from the ear canal of cats [3-6]. The prevalence of $M$. pachydermatis in cats with otitis externa and cats without otitis externa ranges from $24-60 \%$ and $17.6-23 \%$, respectively [36]. Although the prevalence of $M$. pachydermatis in the ear canal of cats has been widely reported around the world [7], studies on the diversity of commensal yeast organisms in healthy cats have been limited. Hair length is a major contributing factor to dermatophytosis in healthy cats [8]. Therefore, lifestyle factors such as hair length, as well as other factors such as season or climate, may contribute to the risk of yeast overgrowth in cats' ears $[8,9]$.

Topical or systemic azole antifungal agents have been widely used in cats with otitis externa and dermatitis associated with Malassezia yeast infections [10, 11]. Several reports of antifungal agent resistance have been recorded due to the inappropriate use of antifungal agents and organisms' genetic mutations [12-15]. Therapeutic failure against $M$. pachydermatis infection in dogs has been reported due to the use of multiple antifungal drugs [12, 13]. However, few researchers have investigated the levels of antifungal susceptibility of yeasts in cats [7]. The aims of this study were to (1) determine the diversity of commensal yeasts in the external aural canal of cats seronegative for feline leukemia virus (FeLV) and feline immunodeficiency virus (FIV), (2) determine lifestyle factors that predispose cats to $M$. pachydermatis, and (3) evaluate the in vitro antifungal susceptibility of $M$. pachydermatis colonizing the external ear canal of cats.

\section{Results}

All 53 cats seronegative for FeLV and FIV infection appeared to be healthy, with no history of ear canal or ear pinna diseases and no history of pruritus. All enrolled cats had no abnormal clinical findings of the external ear canal (a very slight amount of cerumen, no visible color of the cerumen, no ear canal stenosis, no ear pinna erythema, and no otopedal reflex). The demographic characteristics of the cats, including age (mean \pm standard deviation [SD]: 6.04 \pm 3.49 years), sex (male: $62.26 \%$, female: $37.74 \%$ ), body weight (mean \pm SD): $5.08 \pm 1.48 \mathrm{~kg}$ ), breed (Domestic ShortHaired: $45.28 \%$, Bengal: $3.77 \%$, Persian: $33.96 \%$, Maine Coon: 7.55, Mixed Long-Haired: 9.44\%), and cat rearing (indoor only: $90.57 \%$, outdoor access: $9.43 \%)$, are shown in Table 1.
Table 1 Demographic characteristics

\begin{tabular}{ll}
\hline Characteristic & All cats \\
\hline Number & 53 \\
Age (years) & \\
Mean( \pm standard deviation) & $6.04( \pm 3.49)$ \\
Sex (\%; $n)$ & \\
Male & $62.26(33)$ \\
Female & $37.74(20)$ \\
Body weight (kg) & \\
Mean ( \pm standard deviation) & $5.08( \pm 1.48)$ \\
Breed (\%; $n)$ & \\
Domestic Short-Haired & $45.28(24)$ \\
Bengal & $3.77(2)$ \\
Persian & $33.96(18)$ \\
Maine Coon & $7.55(4)$ \\
Mixed Long-Haired(hair shaft length $>3 \mathrm{~cm})$ & $9.44(5)$ \\
Cat rearing (\%; $\mathrm{n})$ & \\
Indoor only & $90.57(48)$ \\
Outdoor access & $9.43(5)$ \\
\hline
\end{tabular}

In the present study, 10 yeast species were identified from the external ear canal of cats: $M$. pachydermatis, Malassezia nana, Malassezia cuniculi, Malassezia furfur, Candida ciferrii, and other yeast species (Aureobasidium melanogenum, Cystobasidium calyptogenae, Moesziomyces aphidis, Rhodotorula mucilaginosa, and Sympodiomycopsis sp.). The prevalence (95\% confidence interval [CI]) of $M$. pachydermatis was $50.94 \%$ (36.84$64.94 \%$; Table 2). The prevalence (95\% CI) of $M$. nana, M. cuniculi, and $M$. furfur was $16.98 \%$ (8.07-29.80), $1.89 \%(0.05-10.07 \%)$, and $1.89 \%$ (0.05-10.07\%), respectively. The prevalence $(95 \% \mathrm{CI})$ of C. ciferrii was $9.42 \%(3.13-20.66 \%)$. The prevalence $(95 \% \mathrm{CI})$ of each of the remaining yeasts (Aureobasidium melanogenum, Cystobasidium calyptogenae, Moesziomyces aphidis, Rhodotorula mucilaginosa, and Sympodiomycopsis sp.) was $1.89 \%(0.05-10.07 \%)$.

The prevalence $(95 \% \mathrm{CI})$ of $M$. pachydermatis among short-haired and long-haired cats was $11.32 \%$ (4.27$23.23 \%)$ and $39.62 \%$ (26.45-54.0\%), respectively (Table 3). There was an association between hair length and a positive culture for $M$. pachydermatis $(p=0.0001)$. The odds $(95 \% \mathrm{CI})$ of a negative culture for $M$. pachydermatis among short-haired cats was 11.67 (3.2242.24) times higher than that among long-haired cats $(p=0.0002)$.

The prevalence $(95 \% \mathrm{CI})$ of $M$. pachydermatis in cats that had been receiving ear cleaning at intervals of $\leq 2$ weeks and > 2 weeks or never was $11.32 \%$ (4.27$23.03 \%)$ and $49.06 \%$ (35.06-63.16\%), respectively. 
Table 2 Prevalence (95\% confidence interval) of 10 identified yeast species

\begin{tabular}{|c|c|c|c|}
\hline \multirow[t]{2}{*}{ Identified yeast genus } & \multicolumn{2}{|l|}{ Number of cats } & \multirow{2}{*}{$\begin{array}{l}\text { Prevalence } \\
\text { (\%; } 95 \% \\
\text { confidence } \\
\text { interval) }\end{array}$} \\
\hline & Negative culture & Positive culture & \\
\hline Malassezia pachydermatis & 26 & 27 & $50.94(36.84-64.94)$ \\
\hline Malassezia nana & 44 & 9 & $16.98(8.07-29.80)$ \\
\hline Malassezia cuniculi & 52 & 1 & $1.89(0.05-10.07)$ \\
\hline Malassezia furfur & 52 & 1 & $1.89(0.05-10.07)$ \\
\hline Candida ciferrii & 48 & 5 & $9.42(3.13-20.66)$ \\
\hline Aureobasidium melanogenum & 52 & 1 & $1.89(0.05-10.07)$ \\
\hline Cystobasidium calyptogenae & 52 & 1 & $1.89(0.05-10.07)$ \\
\hline Moesziomyces aphidis & 52 & 1 & $1.89(0.05-10.07)$ \\
\hline Rhodotorula mucilaginosa & 52 & 1 & $1.89(0.05-10.07)$ \\
\hline Sympodiomycopsis sp. & 52 & 1 & $1.89(0.05-10.07)$ \\
\hline
\end{tabular}

There was an association between ear cleaning frequency and the presence of $M$. pachydermatis ( $p=$ 0.007). The odds $(95 \% \mathrm{CI})$ of a negative culture for $M$. pachydermatis in cats that were receiving ear cleaning at $\leq 2$-week intervals was $5.78(1.67-19.94)$ times higher than among cats receiving ear cleaning at $>2$-week intervals or never $(p=0.0055)$.

The prevalence $(95 \% \mathrm{CI})$ of $M$. pachydermatis in cats aged $\leq 6$ years and $>6$ years was $26.42 \%(15.26-40.33 \%)$

Table 3 Lifestyle factors of cats with a positive culture of Malassezia pachydermatis

\begin{tabular}{|c|c|c|c|}
\hline \multirow[t]{2}{*}{ Lifestyle factors } & \multicolumn{2}{|l|}{ Number of cats } & \multirow[t]{2}{*}{$p$-value } \\
\hline & Negative culture & Positive culture & \\
\hline Hair length & & & 0.0001 \\
\hline Short-haired $(\leq 3 \mathrm{~cm})$ & 20 & 6 & \\
\hline Long-haired $(>3 \mathrm{~cm})$ & 6 & 21 & \\
\hline Ear cleaning frequency & & & 0.007 \\
\hline$\leq 2$ weeks & 12 & 6 & \\
\hline$>2$ weeks or never & 9 & 26 & \\
\hline Age group & & & 0.7846 \\
\hline$\leq 6$ years & 15 & 14 & \\
\hline$>6$ years & 11 & 13 & \\
\hline Bathing frequency & & & 0.0537 \\
\hline$\leq 1$ month & 3 & 10 & \\
\hline$>1$ month or never & 23 & 17 & \\
\hline Cat rearing & & & 0.1917 \\
\hline Indoor only & 22 & 26 & \\
\hline Outdoor access & 4 & 1 & \\
\hline Sex & & & 0.7786 \\
\hline Male & 17 & 16 & \\
\hline Female & 9 & 11 & \\
\hline
\end{tabular}

and $24.53 \%$ (13.75-38.28\%), respectively. The prevalence $(95 \% \mathrm{CI})$ of $M$. pachydermatis in cats that were bathed at intervals of $\leq 1$ month and $>1$ month or never was $18.87 \%$ (9.44-31.97\%) and $32.08 \%$ (19.92-46.32\%), respectively. The prevalence $(95 \% \mathrm{CI})$ of $M$. pachydermatis in indoor-only cats and cats with outdoor access was $49.06 \%(35.06-63.16 \%)$ and $1.89 \%(0.05-10.07 \%)$, respectively. The prevalence $(95 \% \mathrm{CI})$ of $M$. pachydermatis in male cats and female cats was $30.19 \%$ (18.34$44.34 \%)$ and $20.75 \%$ (10.84-34.11\%), respectively. There was no association between a positive culture of $M$. pachydermatis and lifestyle factors such as age $(p=$ $0.7846)$, frequency of bathing $(p=0.0537)$, cat rearing $(p=0.1917)$, and sex $(p=0.7786)$ (Table 3).

The results of the antifungal susceptibility testing for the most common yeast, $M$. pachydermatis, from 27 cats are shown in Table 4. Overall, 41 isolates of M. pachydermatis from these cats were analyzed for antifungal susceptibility. The ranges of the minimum inhibitory concentrations (MICs) for itraconazole (ITZ), ketoconazole (KZ), miconazole (MZ), and terbinafine (TERB) against all isolates of $M$. pachydermatis were $\leq 0.063-4$, $\leq 0.063-8, \leq 0.063-\geq 32$, and $\leq 0.016-1 \mu \mathrm{g} / \mathrm{ml}$, respectively. The ranges of the minimum fungicidal concentrations (MFCs) for ITZ, KZ, MZ, and TERB against all isolates of $M$. pachydermatis were $\leq 0.063-\geq 32$, $0.125-\geq 32,0.5-\geq 32$, and $0.125-8 \mu \mathrm{g} / \mathrm{ml}$, respectively.

\section{Discussion}

In this study, the identified organisms from the external ear canals of 53 cats were Malassezia pachydermatis, Malassezia nana, Malassezia cuniculi, Malassezia furfur, Candida ciferrii, Aureobasidium melanogenum, Cystobasidium calyptogenae, Moesziomyces aphidis, Rhodotorula mucilaginosa, and Sympodiomycopsis sp. The most common positive cultured yeast was $M$. pachydermatis, with 
Table 4 Susceptibility testing for 41 isolates of Malassezia pachydermatis

\begin{tabular}{|c|c|c|c|c|c|c|c|}
\hline \multicolumn{2}{|c|}{ Itraconazole } & \multicolumn{2}{|c|}{ Ketoconazole } & \multicolumn{2}{|c|}{ Miconazole } & \multicolumn{2}{|c|}{ Terbinafine } \\
\hline MIC (n) & MFC (n) & MIC (n) & MFC (n) & MIC (n) & MFC (n) & MIC (n) & MFC (n) \\
\hline $4(1)$ & $\geq 32(1)$ & $8(1)$ & $\geq 32(2)$ & $\geq 32(10)$ & $\geq 32$ (9) & $1(2)$ & $8(4)$ \\
\hline $1(2)$ & $16(1)$ & $2(2)$ & $16(1)$ & $16(1)$ & $16(13)$ & $0.5(5)$ & $4(19)$ \\
\hline $0.5(1)$ & $8(2)$ & $1(5)$ & $8(3)$ & $8(3)$ & $8(14)$ & $0.25(9)$ & $2(12)$ \\
\hline $0.25(4)$ & $1(1)$ & $0.25(15)$ & $4(3)$ & $4(4)$ & $4(2)$ & $0.125(9)$ & $1(5)$ \\
\hline $0.125(1)$ & $0.5(5)$ & $0.125(9)$ & $2(4)$ & $2(13)$ & $2(1)$ & $0.063(8)$ & $0.125(1)$ \\
\hline \multirow[t]{4}{*}{$0.063(32)$} & $0.25(2)$ & $0.063(9)$ & $1(7)$ & $1(1)$ & $1(1)$ & $0.031(2)$ & \\
\hline & $0.125(11)$ & & $0.5(19)$ & $0.5(5)$ & $0.5(1)$ & $0.016(6)$ & \\
\hline & $0.063(18)$ & & $0.25(1)$ & $0.125(1)$ & & & \\
\hline & & & $0.125(1)$ & $0.063(3)$ & & & \\
\hline
\end{tabular}

MIC minimum inhibitory concentration $(\mu \mathrm{g} / \mathrm{ml}) ; N$ represents the number of isolates that presented the indicated MIC or MFC; MFC minimum fungicidal concentration $(\mu \mathrm{g} / \mathrm{ml})$

a prevalence $(95 \% \mathrm{CI})$ of $50.94 \%(36.84-64.94 \%)$. Because of its high abundance, M. pachydermatis was selected in this study of risk factors and susceptibility testing. Lifestyle factors such as hair length and the frequency of ear cleaning contributed to the risk of having a positive culture for $M$. pachydermatis from the cats' external ear canals. This study is the first report of the MICs and MFCs of ITZ, KZ, MZ, and TERB against $M$. pachydermatis in cats.

All 53 enrolled cats were apparently healthy, as confirmed by taking their history and conducting a general physical examination, complete blood count testing, blood chemistry testing, and serology testing for FeLV and FIV infection. All positive cultured organisms from the external ear canal of the cats were considered commensal organisms. The cat's cerumen was initially cultured on various cultured media to increase the variety of isolated yeast organisms followed by polymerase chain reaction (PCR) and DNA sequencing. Conventional yeast identification using culture media is often timeconsuming, and it is difficult to differentiate lipiddependent yeast species (M. nana, M. cuniculi, and $M$. furfur). Molecular identification of yeast species is a quick method to confirm yeast species.

The Malassezia species identified in this study were M. pachydermatis, M. nana, M. cuniculi, and M. furfur. These organisms are commensal yeasts of the ear canal and skin in felids and other domestic animals $[3,5,9$, 16]. The prevalence of $M$. pachydermatis and M. nana has previously been reported in cats without otitis externa to be 13.4-41.1 and $3 \%$, respectively $[6,9,16-$ 18]. The prevalence of $M$. pachydermatis $(40.9 \%)$ and M. nana (16.98\%) in healthy cats from this study was higher than that in previous reports. This discrepancy may be explained by the methods of sample collection and geographic differential effects. Previous studies performed sample collection on the unilateral ear canal [9] and used an antiseptic solution on the ear pinna and canal surface before sample collection [16], whereas samples from this study were collected from both ear canals and did not use any antiseptics on the ear pinna or ear canal surface before sample collection. This may have resulted in an increased number of yeast organisms identified. Moreover, PCR tests and DNA sequencing were also performed in this study to identify the yeast species. Therefore, the prevalence of yeast organisms in this study may truly represent their prevalence better than other studies that used only macroscopic, microscopic, and biochemistry property identification $[9,16]$. In addition, this study was performed in a tropical area. Geographical variation may play an important role in the prevalence of $M$. pachydermatis in this study. Moreover, the presence of $M$. nana has been primarily noted to be in cat external ear canals compared to other body parts, suggesting that this organism is adapted to this anatomical site [18].

Furthermore, this study was the first to report the prevalence of M. cuniculi, M. furfur, C. ciferri, Aureobasidium melanogenum, Cystobasidium calyptogenae, Moesziomyces aphidis, Rhodotorula mucilaginosa, and Sympodiomycopsis sp. in the external ear canal of cats. The genus Candida is an opportunistic pathogen that causes candidiasis and candidaemia in both humans and animals [19]. Aureobasidium melanogenum and Moesziomyces species are opportunistic pathogenic yeasts that cause fungemia [20-22] and trigger hypersensitivity pneumonitis in humans [23]. Rhodotorula spp. is an emergent opportunistic pathogen, particularly in immunocompromised humans $[24,25]$. However, there have been no reports of systemic infection with these pathogens in cats. Additional studies should be performed to identify the pathogenesis of these opportunistic yeast organisms in cats. Moreover, more awareness and additional studies are needed about commensal yeast pathogen transmission from cats to humans within the same household. Cystobasidium calyptogenae and 
Sympodiomycopsis sp. have been reported as environmental yeast organisms in water and soil [26].

It should be noted that the yeasts isolated in this study were present on the skin of the ear canals of healthy cats. The pathogenic roles of these isolated organisms may be related to the host immune response as well as to yeast-specific virulence factors [2, 27]. Cats with FeLV, FIV, and glucocorticoid treatment are predisposed to yeast overgrowth $[11,28]$. Cats with hypersensitivity to yeasts or their metabolites are likely to develop severe skin lesions [2]. Structural malformation of the ear canal, excessive sebum production, and otitis are associated with bacterial and yeast overgrowth [2, 27].

This study investigated the association between the presence of $M$. pachydermatis in the external ear canal of cats and lifestyle factors. Age, bathing frequency, cat rearing, and sex are not commonly considered to be predisposing factors for M. pachydermatis in cats; however, this study confirmed that hair length and the frequency of ear cleaning contribute to the risk of a positive culture for M. pachydermatis from cats' external ear canals. This finding may be explained by the anatomy associated with hair length. For example, long-haired cats have hairs in the ear canal, which may increase its local humidity and the chance of yeast accumulation in the ear canal. $\mathrm{Hu}$ midity and the presence of lipids and sebum may predispose cats to yeast overgrowth, leading to inflammation and the development of pathologic lesions [2].

The MICs of ITZ, KZ, MZ, and TERB against $M$. pachydermatis were evaluated using results modified from a previous report [29-31]. The MIC of ITZ against most isolates of $M$. pachydermatis in our study was $0.063 \mu \mathrm{g} / \mathrm{ml}$ (78.05\%, 32/41 isolated), which was similar to a previous report of antifungal susceptibility levels of ITZ against $M$. pachydermatis isolated from otitis and dermatitis dogs and cats [29, 31]. The highest MIC of ITZ was $4 \mu \mathrm{g} / \mathrm{ml}$, which was consistent with a previous report of high MIC levels of ITZ (4-8 $\mu \mathrm{g} / \mathrm{ml})$ from planktonic cells of $M$. pachydermatis isolated from the skin and scales of dogs [30]. The MICs of KZ at 0.125$0.25 \mu \mathrm{g} / \mathrm{ml}$ observed in $59 \%$ of $M$. pachydermatis isolates in our study were consistent with previous reports $[30,31]$. The highest MIC of $\mathrm{KZ}$ at $8 \mu \mathrm{g} / \mathrm{ml}$ from this study was consistent with previous findings [30, 31].

Most isolates of $M$. pachydermatis (76\%) showed the same range of MICs for MZ, with many reports at $0.063-16 \mu \mathrm{g} / \mathrm{ml}[12,31-35]$. Interestingly, a high MIC of $\mathrm{MZ}$ at $\geq 32 \mu \mathrm{g} / \mathrm{ml}$ was detected in $24 \%$ of our isolates. To our knowledge, the MIC of $\mathrm{MZ}$ at $\geq 32 \mu \mathrm{g} / \mathrm{ml}$ was the highest MIC level that has been reported to inhibit the growth of $M$. pachydermatis from cats. This could be due to antifungal resistance caused by inappropriate uses of MZ, which is commonly included in ear treatment solutions [12].
The MICs of TERB against $M$. pachydermatis were $0.016-1 \mu \mathrm{g} / \mathrm{ml}$, similar to previous reports [29-31, 33, $36,37]$. The sensitivity to TERB may be explained by the limited use of TERB in Thailand to treat animals. Overall, the antifungal susceptibility of all tested drugs against $M$. pachydermatis from the external ear canal of healthy cats was comparable to most studies in animals. Interpretative breakpoints are not available for Malassezia yeasts; nonetheless, high MIC values were recognized for the isolates. Further studies of antifungal susceptibility testing obtained from clinically related isolates and reports of treatment failure are necessary.

\section{Conclusions}

The present study revealed that $M$. pachydermatis was the most commonly isolated yeast organism from cats' external ear canals. Hair length and frequency of ear cleaning played a role in the presence of $M$. pachydermatis. All M. pachydermatis isolates had various MIC levels against common fungicides.

\section{Methods \\ Animals}

A prospective cross-sectional study was performed at Kasetsart University Veterinary Teaching Hospital, Faculty of Veterinary Medicine, Bangkok, Thailand, from March to December 2020. Fifty-three healthy cats were enrolled in this study. None of the cats had an illness or required any kind of medical treatment for at least 3 months prior to the study. The age $(\leq 6$ years and $>6$ years), sex (male and female), breed, and body weight of each cat were recorded. In addition, the lifestyle factors of the individual cats were assessed, including their hair length (short-haired and long-haired), frequency of ear cleaning ( $\leq 2$ weeks and $>2$ weeks or never), frequency of bathing ( $\leq 1$ month and $>1$ month or never), and history of cat rearing (indoor only and outdoor access). A general physical examination, complete blood count, and blood chemistry testing (blood urea nitrogen, creatinine, serum glutamate pyruvate transaminase, total protein, and albumin) were performed on all cats. A commercially available FeLV-FIV rapid immunochromatography test assay (Witness ${ }^{\oplus}$, Lyon Cedex, France) was used to determine FeLV and FIV infection.

\section{Dermatological examination and specimen collection}

Bilateral otoscopic examination of the ear pinnae and ear canal was performed on all of the cats. The appearance of the ear pinnae and the otopedal reflex were characterized and recorded according to the criteria of the clinical findings of the external ear canal, including the history of pruritus (absent or present), amount of cerumen (very slight, slight, or moderate to severe cerumen), the color of the cerumen (none visible, white, or 
yellow), ear canal stenosis (absent or present), erythematous (absent or present), and the otopedal reflex (absence or present) $[38,39]$. Sterile cotton swabs were used for external ear canal sample collection for yeast isolation.

\section{Yeast isolation and phenotypic identification}

An external ear canal swab was inoculated on culture media consisting of Sabouraud dextrose agar (SDA) (Difco, USA), Leeming and Notman agar (LNA) [40], and mycobiotic agar (Acumedia, MI, USA). Oxytetracycline $(50 \mathrm{mg} / \mathrm{L}$; Oxycline, Bangkok, Thailand) was added to all culture media to inhibit bacterial growth and allow the commensal yeasts to grow and easily be isolated. All cultured plates were incubated at $30{ }^{\circ} \mathrm{C}$ and examined daily for colony growth for 14 days. The growth rate, colony morphology, and microscopic features of the yeasts on each agar type were observed. To presumptively identify the yeast genus, a urea hydrolysis test was performed on all isolates.

All isolates of Malassezia yeasts were presumptively identified to the species level according to their lipid dependency and utilization from various lipid tests, including growth on lipid-free medium SDA, the utilization of castor oil (Cremophor EL, EL slant; Sigma-Aldrich, MO, USA), utilization of Tween 60-esculin agar (TE slant), and a Tween assimilation test [40].

\section{DNA extraction, PCR amplification, and DNA sequencing}

DNA extraction was modified from a previous report [41]. In brief, lysis buffer solution comprised of sodium dodecyl sulfate salt (0.5 g; Himedia, Mumbai, India), $\mathrm{NaCl}$ (1.4 g; Carlo Erba, MI, USA), EDTA (0.73 g; Biobasic, Ontario, Canada), $1 \mathrm{M}$ Tris- $\mathrm{HCl}(20 \mathrm{ml}$; Biobasic, Ontario, Canada) and 2-mercaptoenol (5 $\mu \mathrm{l}$; SigmaAldrich, Steinheim, Germany) was added to the freezeharvested yeast cells and they were incubated at $65{ }^{\circ} \mathrm{C}$ for $1 \mathrm{~h}$ (vortexed at least once during incubation). The lysate was purified using $500 \mu \mathrm{l}$ of phenol:chloroform: isoamyl alcohol solution (vol:vol:vol of 25:24:1). The yeast suspension was thoroughly mixed by vortexing for 2 min to obtain a homogeneous suspension and then centrifuged at $14,000 \mathrm{rpm}$ for $15 \mathrm{~min}$. The clear upper aqueous phase was transferred to a new tube, an equal volume of cold isopropanol was added, and the tube was kept at $-20{ }^{\circ} \mathrm{C}$ overnight. The DNA was precipitated by centrifugation at $14,000 \mathrm{rpm}$ and $4{ }^{\circ} \mathrm{C}$ for $20 \mathrm{~min}$. Then, the DNA pellet was washed with $500 \mu \mathrm{l}$ of $70 \%$ ethanol and air-dried, dissolved in molecular-grade water, measured for DNA concentration using a NanoDrop (Thermo Scientific, MA, USA), and stored at $-20{ }^{\circ} \mathrm{C}$ until use.

The internal transcribed spacer (ITS) region of the ribosomal DNA gene of all DNA samples was amplified using the primer set SR6R (5'-AAGTATAAGTCGTA ACAAGG-3') and ITS4 (5'-TCCTCCGCTTATTGAT ATGC-3') [42]. The PCR amplicons were visualized by $1.5 \%$ agarose gel (Serva, Heidelberg, Germany) electrophoresis; all PCR products were purified and sequenced in both the forward and reverse directions using $A B I$ BigDye Terminator v.3.1 (Macrogen Inc., South Korea).

The sequences were assembled bidirectionally and manually corrected for consensus sequences using BioEdit v.7.2.5 (https://bioedit.software.informer.com). Sequence similarity was searched using the BLASTn tool of the National Center for Biotechnology Information (http://blast.ncbi.nlm.nih.gov/Blast.cgi). The species identity of each yeast isolate was determined based on the sequence similarity of the ITS sequence. DNA alignment and phylogenetic analysis were performed using Molecular Evolution Genetics Analysis (MEGA X version 10, Pen State University, PA, USA). Gene sequencing of all representative isolates was submitted to GenBank (accession numbers: MW793487, MW815503, MW815569, MW816105, MW816147, MW816540, MW816624, MW816629, MW816824, MW816825, MW816915, MW816924, MW817021, MW817088, MW819644. MW819645, MW819646, MW819853, MW819854, MW824435, MW824436, MW824437, MW824438, MW824439, MW824440, MW824441, MW824442, MW824443, MW824444, MW824445, MW824446, MW824447, MW824448, and MW824449).

\section{Antifungal susceptibility testing}

Antifungal susceptibility testing of $M$. pachydermatis, the most common isolated yeast species in this study, was performed in duplicate following the Clinical and Laboratory Standards Institute broth microdilution method (CLSI M27-A3) [43], using a modified version of the method described by Alvarez-Perez et al. [44]. Sabouraud dextrose broth (SDB) supplemented with $1 \%$ Tween 80 (Sigma-Aldrich, MO, USA) was used as a diluting and culture medium in all steps of the antifungal susceptibility testing. The susceptibility of $M$. pachydermatis to the following antifungal agents was tested: ITZ (Sigma-Aldrich, MO, USA), KZ (Sigma-Aldrich, USA), MZ (Sigma-Aldrich, MO, USA), and TERB (Sigma-Aldrich, MO, USA). The final concentrations of the antifungal agents ITZ, KZ, and MZ were prepared at 10 different concentrations $(0.063,0.125,0.25,0.5,1,2,4,8$, 16 , and $32 \mu \mathrm{g} / \mathrm{ml}$ ). TERB was prepared in concentrations of $0.016,0.031 .0 .063,0.125,0.25,0.5,1,2,4$, and $8 \mu \mathrm{g} /$ $\mathrm{ml}$. The broth microdilution method was performed in 96-well microtiter plates (Sigma-Aldrich, MO, USA). The M. pachydermatis inoculum size was measured by spectrophotometry at $530 \mathrm{~nm}$ and adjusted with culture medium to obtain a final cell concentration of $5 \times 10^{3}$ $1 \times 10^{4} \mathrm{CFU} / \mathrm{ml}$. Candida parapsilosis ATCC 22,019 was 
included as the quality control isolate. After incubating at $30{ }^{\circ} \mathrm{C}$ for $72 \mathrm{~h}$, MIC was determined by naked-eye visualization, and MFC was determined after $72 \mathrm{~h}$ of incubation by transferring $200 \mu \mathrm{l}$ of suspension from all wells showing no visible growth to newly fresh SDB with $1 \%$ Tween 80 . The tubes were incubated at $30{ }^{\circ} \mathrm{C}$, and the MFC was defined as the lowest concentration showing complete growth inhibition as demonstrated by the clear subculture tubes.

\section{Statistical methods}

Significance was set at $p<0.05$. The prevalence and $95 \%$ $\mathrm{CI}$ of each yeast organism in the external aural canal in long-haired and short-haired cats were determined. A normality test was performed for all data using the Shapiro-Wilk test. Fisher's exact test was used to analyze the association between lifestyle factors and the presence of M. pachydermatis.

\section{Abbreviations \\ Cl: Confidence interval; FeLV: Feline leukemia virus; FIV: Feline immunodeficiency virus; ITS: Internal transcribed spacer; ITZ: Itraconazole; KZ: Ketoconazole; LNA: Leeming and Notman agar; MFC: Minimum fungicidal concentration; MIC: Minimum inhibitory concentration; MZ: Miconazole; PCR: Polymerase chain reaction; SD: Standard deviation; SDA: Sabouraud dextrose agar; SDB: Sabouraud dextrose broth; TERB: Terbinafine}

\section{Acknowledgements}

The authors wish to thank the cat-friendly clinic at Kasetsart University for assisting with sample collection. We also thank Zoetis, Thailand, for providing a FeLV-FIV rapid immunochromatography test assay (Witness', Lyon Cedex, France).

\section{Authors' contributions}

SN designed the study, conducted the literature review, performed the study, interpreted the data, and drafted the manuscript. CY designed the study, performed the study, and reviewed the manuscript. NT: designed the study and reviewed manuscript. PS designed the study, interpreted the data, and reviewed the manuscript. All authors have read and approved the final manuscript.

\section{Funding}

This research is supported in part by the Graduate Program Scholarship from The Graduate School, Kasetsart University.

\section{Availability of data and materials}

The data used and/or analyzed in the present study are available in the GenBank repository, accession numbers (MW793487, MW815503, MW815569, MW816105, MW816147, MW816540, MW816624, MW816629, MW816824, MW816825, MW816915, MW816924, MW817021, MW817088, MW819644. MW819645, MW819646, MW819853, MW819854, MW824435, MW824436, MW824437, MW824438, MW824439, MW824440, MW824441, MW824442, MW824443, MW824444, MW824445, MW824446, MW824447, MW824448, and MW824449). The phylogenetic data and the alignments have been stored in TreeBASE with a submission ID of 28,179 (accession URL: http://purl.org/ phylo/treebase/phylows/study/TB2:S28179)

\section{Declarations}

\section{Ethics approval and consent to participate}

This animal use protocol was submitted and reviewed by the Kasetsart University Institutional Animal Care and Use Committee (ID\# ACKU63-VET001) and found to be in accordance with the guidelines of animal care and use from the Ethical Review Board of the National Research Council of Thailand for the conduct of scientific research. The committee approved and permitted the animal care and use to be conducted as stated in the animal use protocol for this research study. The study was carried out in compliance with the ARRIVE guidelines.

\section{Consent for publication}

Not applicable.

\section{Competing interests}

The authors declare that they have no competing interests.

\section{Author details}

${ }^{1}$ Graduate Student in Veterinary Clinical Studies, Faculty of Veterinary Medicine, Kasetsart University, 10900 Bangkok, Thailand. ²Department of Microbiology and Immunology, Faculty of Veterinary Medicine, Kasetsart University, 10900 Bangkok, Thailand. ${ }^{3}$ Department of Companion Animal Clinical Sciences, Faculty of Veterinary Medicine, Kasetsart University, 50 Ngamwongwan Rd, Latyao, Jatujak, 10900 Bangkok, Thailand.

Received: 16 April 2021 Accepted: 17 August 2021

Published online: 28 August 2021

\section{References}

1. Khosravi A, Eidi S, Ziglari T, Bayat M. Isolation and differentiation of Malassezia species isolated from healthy and affected small animals, ear and skin. WJZ. 2008:3:77-80.

2. Lautert C, Ferreiro L, Jesus FPK, Zanette TA, Mahl DL, Alves SH, et al. Enzymatic characterization of Malassezia pachydermatis isolates from dogs. Afr J Microbiol Res. 2011;5:2986-90.

3. Crespo MJ, Abarca ML, Cabañes FJ. Occurrence of Malassezia spp. in the external ear canals of dogs and cats with and without otitis externa. Med Mycol. 2002:40:115-21.

4. Dizotti CE, Coutinho SDA. Isolation of Malassezia pachydermatis and M. sympodialis from the external ear canal of cats with and without otitis externa. Acta Vet Hung. 2007;55:471-7.

5. Nardoni S, Mancianti F, Rum A, Corazza M. Isolation of Malassezia species from healthy cats and cats with otitis. J Feline Med Surg. 2005;7:141-5.

6. Shokri H, Khosravi A, Rad M, Jamshidi S. Occurrence of Malassezia species in Persian and domestic short hair cats with and without otitis externa. J Vet Med Sci. 2010;72:293-6.

7. Guillot J, Bond R. Malassezia yeasts in veterinary dermatology: an updated overview. Front Cell Infect Microbiol. 2020:10:79.

8. Sattasathuchana P, Bumrungpun C, Thengchaisri N. Comparison of subclinical dermatophyte infection in short-and long-haired cats. Vet World. 2020;13:2798

9. Cafarchia C, Gallo S, Capelli G, Otranto D. Occurrence and population size of Malassezia spp. in the external ear canal of dogs and cats both healthy and with otitis. Mycopathologia. 2005;160:143-9.

10. Bond R, Guillot J, Cabañes FJ. Malassezia yeasts in animal disease. In: Malassezia and the skin. Springer; 2010. p. 271-99.

11. Velegraki A, Cafarchia C, Gaitanis G, latta R, Boekhout T. Malassezia infections in humans and animals: pathophysiology, detection, and treatment. PLoS Pathog. 2015;11:e1004523.

12. Chiavassa E, Tizzani P, Peano A. In vitro antifungal susceptibility of Malassezia pachydermatis strains isolated from dogs with chronic and acute otitis externa. Mycopathologia. 2014;178:315-9.

13. Watanabe $\mathrm{S}$, Koike $\mathrm{A}$, Kano R, Nagata $\mathrm{M}$, Chen $\mathrm{C}$, Hwang $\mathrm{CY}$, et al. In vitro susceptibility of Malassezia pachydermatis isolates from canine skin with atopic dermatitis to ketoconazole and itraconazole in East Asia. J Vet Med Sci. 2014;76:579-81.

14. Kano R, Yokoi S, Kariya N, Oshimo K, Kamata H. Multi-azole-resistant strain of Malassezia pachydermatis isolated from a canine Malassezia dermatitis. Med Mycol. 2019;57:346-50

15. Kim M, Cho YJ, Park M, Choi Y, Hwang SY, Jung WH. Genomic tandem quadruplication is associated with ketoconazole resistance in Malassezic pachydermatis. J Microbiol Biotechnol. 2018;28:1937-45.

16. Dizotti C, Coutinho S. Isolation of Malassezia pachydermatis and $M$. sympodialis from the external ear canal of cats with and without otitis externa. Acta Vet Hung 2007;55:471-7.

17. Singh AD, Banerjee A, Debnath C, Batabyal K. Conventional characterization and PCR based diagnosis of Malassezia pachydermatis from cerumen of healthy Indian cats. Int J Livest Res. 2020;10:57-61. 
18. Volk AV, Belyavin CE, Varjonen K, Cadiergues MC, Stevens KB, Bond R. Malassezia pachydermatis and M. nana predominate amongst the cutaneous mycobiota of Sphynx cats. J Feline Med and Surg, 2010;12:91722.

19. Pettinari I, Leonardi L, Diguta C, Matei F. Candida infection in humans and animals. AgroLife Sci J. 2019;8:214-9.

20. Wang M, Danesi P, James TY, Al-Hatmi AMS, Najafzadeh MJ, Dolatabadi S, et al. Comparative pathogenicity of opportunistic black yeasts in Aureobasidium. Mycoses. 2019;62:803-11.

21. Mershon-Shier KL, Deville JG, Delair S, Fothergill AW, Wickes B, de Hoog GS, et al. Aureobasidium pullulans var. melanigenum fungemia in a pediatric patient. Med Mycol. 2011;49:80-3.

22. Liu Y, Zou Z, Hu Z, Wang W, Xiong J. Morphology and molecular analysis of Moesziomyces antarcticus isolated from the blood samples of a Chinese patient. Front Microbiol. 2019:10:254.

23. Ziegler K, Joest M, Turan N, Schmidt D, Rath PM, Steinmann J. Hypersensitivity pneumonitis of a bagpipe player: fungal antigens as trigger? Med Mycol Case Rep. 2019;24:44-7.

24. Capoor MR, Aggarwal S, Raghvan C, Gupta DK, Jain AK, Chaudhary R. Clinical and microbiological characteristics of Rhodotorula mucilaginosa infections in a tertiary-care facility. Indian J Med Microbiol. 2014;32:304.

25. Mixão V, Saus E, Hansen AP, Lass-Florl C, Gabaldón T. Genome assemblies of two rare opportunistic yeast pathogens: Diutina rugosa (syn. Candida rugosa) and Trichomonascus ciferrii (syn. Candida ciferrii). G3 (Bethesda) 2019; 9:3921-7.

26. Yurkov AM, Kachalkin AV, Daniel HM, Groenewald M, Libkind D, de Garcia V, et al. Two yeast species Cystobasidium psychroaquaticum fa sp. nov. and Cystobasidium rietchieii fa sp. nov. isolated from natural environments, and the transfer of Rhodotorula minuta clade members to the genus Cystobasidium. Antonie Van Leeuwenhoek. 2015;107:173-85.

27. Babić S, Pašić Š, Zahirović AJV. Prevalence of Malassezia pachydermatis in atopic dogs-50 cases. Veterinaria. 2020;69(2):121-7.

28. Reche Jr A, Daniel AG, Strauss TCL, Taborda CP, Vieira Marques SA, Haipek K, Oliveira LJ, Monteiro JM, Kfoury Jr JR. Cutaneous mycoflora and CD4: CD8 ratio of cats infected with feline immunodeficiency virus. 2010;2(4):355-8.

29. Álvarez-Pérez S, García ME, Peláez T, Blanco JL. Genotyping and antifungal susceptibility testing of multiple Malassezia pachydermatis isolates from otitis and dermatitis cases in pets: is it really worth the effort? Med Mycol. 2016;54:72-9.

30. Brilhante RSN, Rocha MGD, Guedes GMM, Oliveira JS, Araújo GDS, España JDA, et al. Malassezia pachydermatis from animals: planktonic and biofilm antifungal susceptibility and its virulence arsenal. Vet Microbiol. 2018;220: 47-52.

31. Peano A, Johnson E, Chiavassa E, Tizzani P, Guillot J, Pasquetti M. Antifungal resistance regarding Malassezia pachydermatis: where are we now? J Fungi (Basel). 2020;6:93.

32. Hensel P, Austel M, Wooley RE, Keys D, Ritchie BW. In vitro and in vivo evaluation of a potentiated miconazole aural solution in chronic Malassezia otitis externa in dogs. Vet Dermatol. 2009;20:429-34

33. Cafarchia C, Figueredo LA, latta R, Montagna MT, Otranto D. In vitro antifungal susceptibility of Malassezia pachydermatis from dogs with and without skin lesions. Vet Microbiol. 2012;155:395-98.

34. Peano A, Beccati $M$, Chiavassa $E$, Pasquetti M. Evaluation of the antifungal susceptibility of Malassezia pachydermatis to clotrimazole, miconazole and thiabendazole using a modified CLSI M27-A3 microdilution method. Vet Dermatol. 2012;23:131-5

35. Weiler CB, de Jesus FPK, Nardi GH, Loreto ES, Santurio JM, Coutinho SD. Susceptibility variation of Malassezia pachydermatis to antifungal agents according to isolate source. Braz J Microbiol. 2013;44:174-8.

36. Figueredo LA, Cafarchia C, Otranto D. Antifungal susceptibility of Malassezia pachydermatis biofilm. Med Mycol. 2013;51:863-7.

37. Murai T, Nakamura Y, Kano R, Watanabe S, Hasegawa A. Susceptibility testing of Malassezia pachydermatis using the urea broth microdilution method. Mycoses. 2002:45:84-7.

38. Pressanti C, Drouet C, Cadiergues MC. Comparative study of aural microflora in healthy cats, allergic cats and cats with systemic disease. J Feline Med. 2014;16:992-6.

39. Tyler S, Swales N, Foster AP, Knowles TG, Barnard N. Otoscopy and aural cytological findings in a population of rescue cats and cases in a referral small animal hospital in England and Wales. J Feline Med Surg. 2020;22(2): $161-7$.
40. Kaneko T, Makimura K, Abe M, Shiota R, Nakamura Y, Kano R, et al. Revised culture-based system for identification of Malassezia species. J Clin Microbiol. 2007;45:3737-42.

41. Ferrer C, Colom F, Frasés S, Mulet E, Abad JL, Alió JL. Detection and identification of fungal pathogens by PCR and by ITS2 and $5.8 \mathrm{~S}$ ribosomal DNA typing in ocular infections. J Clin Microbiol. 2001;39:2873-79.

42. Duangkaew L, Yurayart C, Limsivilai O, Chen C, Kasorndorkbua C. Cutaneous sporotrichosis in a stray cat from Thailand. Med Mycol Case Rep. 2019;23:46-9.

43. Pfaller M, Diekema D. Progress in antifungal susceptibility testing of Candida spp. by use of Clinical and Laboratory Standards Institute broth microdilution methods, 2010 to 2012. J Clin Microbiol. 2012;50:2846-56.

44. Alvarez-Perez S, Garcia ME, Blanco JL. In vitro activity of amphotericin Bazole combinations against Malassezia pachydermatis strains. Med Mycol. 2019;57:196-203.

\section{Publisher's Note}

Springer Nature remains neutral with regard to jurisdictional claims in published maps and institutional affiliations.
Ready to submit your research? Choose BMC and benefit from:

- fast, convenient online submission

- thorough peer review by experienced researchers in your field

- rapid publication on acceptance

- support for research data, including large and complex data types

- gold Open Access which fosters wider collaboration and increased citations

- maximum visibility for your research: over $100 \mathrm{M}$ website views per year

At BMC, research is always in progress.

Learn more biomedcentral.com/submissions 